\title{
ETHNIC ATTITUDES AND PREJUDICE WITHIN THE SYSTEM OF MULTICULTURAL EDUCATION
}

In the process of multicultural education and reaching its humane objective we often hit the barrier of prejudice. In order to reduce prejudice it is necessary to be aware of the fact that it means a long-term influence by which prejudice can be at least reduced, if not completely eliminated. Negative attitudes or even prejudices at the point of meeting of two different ethnic groups can also be seen among children. The area of ethnic and racial attitudes was the subject of survey, in which we examined positive or negative opinions of the elementary school pupils concerning selected ethnic and racial groups they can get in contact with.

\section{Introduction}

The problem of ethnic attitudes and prejudice is an essential issue of multicultural education. Relationships between individuals originating from different ethnic groups can take different forms such as indifference, friendship, or even hatred. These relationships are influenced by a great number of factors. They are, for example, determined by the overall character of the relationships between particular ethnic groups, as well as various situational and personal factors. The above mentioned factors influence the way we perceive or assess the other party, and what qualities we associate with them, i.e. what attitude we take.

\section{Ethnic attitudes and their structure}

An attitude is a psychological category and psychology defines it as a tendency that has an impact on the particular behaviour of an individual. Nákonečný [6] considers an attitude to be either a positive or negative relation to reality, so in general it expresses acceptance or rejection of a certain phenomenon, attraction or resistance to it.

When speaking of ethnic attitudes, we usually mean inter-ethnic attitudes, while there are also attitudes of an individual to the members of their own ethnic group, i.e. intra-ethnic attitudes. The concept of ethnic attitudes often includes attitudes to the individuals or groups identified on the racial basis. The structure of an ethnic attitude can be viewed as a three-component category. From this point of view, an attitude consists of:

- knowledge, information, opinions of an ethnic character (cognitive component),

- emotional assessment of a relationship (affective component),

- tendency to a certain behaviour in an interethnic relationship (behavioural component)
The precondition for forming ethnic attitudes is reaching a certain level of ethnic self-awareness, i.e. at least differentiation of an own ethnic group from the others. Other preconditions include intellectual and social maturity of an individual. An attitude does not arise in one day, its forming is a gradual process and it continues changing throughout the life.

Ethnic attitudes of pupils are not created according to any internal plan, but as a result of their interaction with the environment. The quality of this interaction directly influences the quality of their attitudes. Therefore it is necessary to consider the values we offer them in the process of education and socialization.

\section{Ethnic prejudice and their sources}

Elimination or reduction of racial and ethnic prejudice is often presented as an objective of multicultural education. Prejudice represents a special kind of bias, a predetermined negative attitude based on belief which implies unquestionable expectation of a negative, hostile behaviour of another person or another group of people. It represents the acquired negative schemes which significantly influence assessment and behaviour and which, in contact with a person associated with the prejudice, trigger the defence mechanism that essentially changes human behaviour [1].

Psychologists deal with a question how prejudices arise and what is the cause of a fact that they can lead to extreme hatred of the other ethnic groups. Allport [3] defines five development stages of ethnic prejudice, appearing in societies tolerating racism.

1. Libel - unfriendly talk, false information, racist propaganda.

2. Isolation - separation of an ethnic group, most frequently a minority, from a dominant ethnic group.

3. Discrimination - minorities' fundamental human and civil rights are challenged. The principle of equal chances for getting a job, housing etc. does not account to them.

\footnotetext{
* Dagmar Kováčiková

Department of Paedagogics, Faculty of Paedagogics, UMB, Banská Bystrica, Slovakia, E-mail: dkovacikova@pdf.umb.sk
} 
4. Physical aggression - violence against persons and their property is concerned. It can be committed by individuals but usually racist organizations or, in extreme cases, even the government/state are involved.

5. Genocide - violence against the whole ethnic group, while the goal is its total liquidation.

In the process of realization of multicultural education and meeting its humane objective of tolerant co-existence of various ethnic groups, the educationists inevitably hit the barrier of prejudice. Biased opinions can already be found with children and they are directed against ethnic groups, both geographically near and far. Their sources and the process of origination are very complex It is generally assumed that their sources are the factors of social micro-environment such as the family in which the child is being brought up, the relatives, peers and friends, as well as the factors of social macro-environment. These include school education, the impact of the media and general views held in the society. Both types of factors affect the children since their young age. Apart from them, however, there can also be extraordinary factors such as war conflict, strongly negative personal experience etc.

\section{Elimination of racial prejudice}

Naturally, the analysis of possible sources of prejudice itself is not enough. Practical life requires possible ways of elimination, or at least reduction of prejudice. If we want to achieve the required change, i.e. reduction of prejudice, it is necessary to be aware of the following:

- Attitudes accepted by the society significantly influence human behaviour. Therefore it is necessary to create such a climate in the society that will not encourage prejudice, not even indirectly.

- There is a greater chance of creating prejudice in a situation where there is a lack of information; hence increase in informedness is also a preventive step against bias.

- Intelligence and education are in a negative relation with prejudice. All of those participating in the process of education should be especially aware of this fact and see education as an effective tool in the fight against intolerance among people, the ethnically-motivated one too, of course.

- Children acquire prejudice from those they are in close contact with. In this respect it is necessary to be aware of the power of a personal positive model for each child. It is very likely that if children are brought up in the environment without prejudice, they will stay without prejudice.

When trying to affect prejudice, we need to be ready for a long process as the core of prejudice is irrational and resistant against any rational argumentation. Although we do not succeed to eliminate prejudice in total, we can at least reduce it. Hayes [3] defines five basic conditions of its reduction among pupils:

1. The participants must have equal position. This is also important in groups of pupils. The pupils should be able to see and experience that the child of a different colour of skin is clever, can make something nice or be positively exceptional in another way. That can lead to a change of attitudes among the dominant majority. On the contrary, one-sided preference of the majority individuals leads to the feelings of inferiority among the children from the other ethnic groups and thus creates background for unequal relationships and prejudice.

2. There must be an opportunity to have a personal contact. The fact that the conflict groups or individuals meet does not guarantee that they will alter their prejudice. If we want the pupils to reconsider their opinions, we must allow the children from ethnically different groups to get to know each other. Better knowledge of personal characteristics can even lead to more acceptation.

3. Contact with non-stereotype individuals. We are naturally led by prejudice to stereotypical perception of all members of a different group. However, if pupils frequently meet the members who do not match this stereotype, they are forced to reconsider their views. Thus they learn to notice and respect human uniqueness rather than racial or ethnic membership.

4. Social support of contact among groups. This condition is closely related not only to the climate in the society, but also in a particular social environment of a pupil. Hope that the contact with another ethnic group will reduce prejudice can be greater if the pupil is encouraged by the family, friends and school indeed.

5. Opportunities to cooperate. An experience with solving a common problem or task with an ethnically different individual leads the pupils to broadening the social limits of their social identification. In such cases differentiation between "us" and "them" disappears and need for cooperation leads to overcoming differences between groups.

Elimination or reduction of prejudice is generally very difficult, which is caused mainly by their strong emotional charge, while their rational aspect is usually suppressed. Since most prejudices arise in a family, cooperation with the pupils_families is of great importance [2].

\section{Views of the elementary school pupils concerning the selected ethnic and racial groups}

Negative attitudes or even prejudices, or group conflicts at the point of meeting two different ethnic groups can already be seen among children. The area of ethnic and racial attitudes was a subject of our survey, in which we studied positive or negative views of the elementary school pupils concerning the selected ethnic and racial groups that the pupils are likely to get in contact with. By means of a modified Bogardus social distance scale and group discussions with pupils we tried to determine the rate of acceptance or rejection of the selected ethnic and racial groups by 109 pupils of the Forms 8 and 9 of elementary school [4]. In this context we have identified ethnic groups with the highest and the lowest number of negative responses.

As the table shows, the most rejected ethnic group is the Roma minority, with the total rejection rate of $59.72 \%$. Reasons for rejection, according to the pupils, are many. Most pupils have a negative view of the Romany_s attitude to work which they qualify 
The chart of the rejected ethnic groups

\begin{tabular}{|c|c|}
\hline Ethnic group & Rejection rate \\
\hline Romany & $59.72 \%$ \\
\hline Arabs & $42.11 \%$ \\
\hline Hungarians & $39.45 \%$ \\
\hline Chinese & $27.89 \%$ \\
\hline black people & $23.67 \%$ \\
\hline Russians & $16.88 \%$ \\
\hline Americans & $9.27 \%$ \\
\hline Czechs & $6.79 \%$ \\
\hline
\end{tabular}

as indifferent. There were objections against their low level of education, their backwardness. They see them as people whose children often do not go to school and generally resist progress. The pupils also negatively perceive weak adaptation ability of the Romany and their lack of willingness to adapt to the majority population.

Arabs took, in the framework of our survey, the position of the second least welcome ethnic group. With regard to our findings we can state that the main reason of their rejection by the pupils is the association of this ethnic group with terrorist attacks and other forms of radical behaviour. These evoke the feelings of menace in the pupils, and the consequent need to keep their distance from the Arabs.

The position of Hungarians in the survey was rather close to the one of Arabs. We can state that most objections against the Hungarians concerned either history or the present state of SlovakHungarian relations at the national level. The pupils showed strong disagreement with the fact that South Slovakia is "hungarized". Fewer objections concerned Hungarian language and character qualities of the Hungarian people. On the other hand, there were also pupils who quite like Hungarians, consider them interesting and, despite the different language, rather similar to us.

Ethnic groups that took the following positions in our survey were viewed less critically by the pupils and the proportion of positive and negative judgement was more balanced. This advancement can be also seen in the assessment of the Chinese. Some pupils dislike expansion of the Chinese shops and goods which they regard to be low-quality. They also believe that the Chinese are a threat because of taking our jobs and having a destructive impact on our traders. These opinions reveal that the pupils often copy the opinions of their parents and environment as in their age they are not very likely to notice changes on the job market and in business. Many other pupils, however, think the Chinese seem to be likeable. Despite that most of them refuse closer relationships with them as they only know them from the shops.

Black people, who took the following position, were according to verbal assessment of the pupils viewed quite positively. Similarly to the Chinese, they were rejected mostly in close relationships which was caused more by xenophobic feelings that rational argu- ments. The pupils like black music and lifestyle, they consider black people to be kind-hearted, funny and charismatic. Sometimes they mentioned their ignorance, backwardness and low material standard. In such cases, however, contrarily to the Romany, they feel this is a result of their discrimination in the past and present and so it is necessary to help them.

Compared to the other ethnic groups, there were rather few specific responses concerning the members of a Russian one. The pupils emphasized the lack of direct contact with the Russians. Some of them had some information (about the country, economic differences among its inhabitants) from their parents, or from school. They remembered several events from Russian history but they did not mention the period before 1989, when the connection between our country and Russia was very intensive.

Compared to the Russians, the issue of attitudes towards the Americans rang the bell, which is probably caused by the general situation in the society. The Americans are the subject of both admiration and criticism, especially because of their foreign politics. On the basis of the authentic discourses we have concluded that the Americans, and particularly their lifestyle, are perceived the least realistically by the pupils when compared to the other ethnic groups. They said that they would like to live there one day because of a number of opportunities, higher salaries and generally better conditions for living. Consequently, they perceive the Americans as wise, intelligent, progressive. They presented several views such as "the Americans are good-looking, famous and surely very kind". Many of them expressed their wish to visit this country, learn about its interesting culture and improve the language. In opposition to these views there was criticism of American politics and typical American behaviour which the pupils qualify as arrogant. According to their own judgement, the Americas are trying to rule the world, refuse to admit any mistakes and control everyone. Even the ordinary Americans are, allegedly, complicated people, superficial, greedy and very lofty. It was clear from the pupils' opinions that their perception of the Americans, both positive and negative, is determined predominantly by the media and prevailing public opinion. Their attitudes towards the Americans also reflect their values, or the values of their families, as far as the American lifestyle is concerned. Obviously, here we can see profiles of two groups of pupils whose views are completely contradictory.

The most positively accepted ethnic group is, according to our survey, the Czech one. Most pupils held positive views of them, as expected. The reason for this positive attitude was common history of the Slovak and Czech nations, until recently existing common state and comprehensibility of the Czech language. The pupils often viewed the Czechs as our friends or even brothers and highlighted the fact that Czechs are like Slovaks. This positive perception is surely influenced by the fact that many of them have relatives or acquaintances in the Czech Republic and some have already found many friends among young Czechs. They characterize them as nice, funny and polite. For the sake of complete picture, however, we need to add that Czechs are also viewed negatively by some pupils who see them, especially in relation to Slovaks, as lofty and superior. 
Apart from the above mentioned we also need to say that despite many negative attitudes against the examined ethnic groups, some pupils showed their positive view of all the ethnic groups. This is a gratifying finding as we are approaching multiethnic society where the core of coexistence should be mutual respect of everyone's personality with recognition of their dignity. It means everyone's right to respect and proper treatment, right to such behaviour that does not allow discrimination, constraint and degradation. It also means fight against intolerance and its extreme forms such as racism and xenophobia.

\section{Conclusion}

In conclusion it is necessary to point out that it would be an illusion to think multicultural education realized either inside or outside school can satisfactorily solve all the problems of ethnic prejudice. The issue is much larger and concerns the whole society.

\section{References}

[1] CABANOVÁ, V:: Culture and balancing cultural differences in school education (inclusiveness and strategies supporting school success), Metodicko-pedagogické centrum, Prešov, 2006, ISBN 80-8045-414-0

[2] CABANOVÁ, V.: Contra-prejudice education as a part of multiethnic education, Family and School, 2/2006, p.10

[3] HAYESOVÁ, N.: Introduction to social psychology, $1^{\text {st }}$ edition, Praha, 1998, p. 168, ISBN 80-7178-198-3

[4] GULAČOVÁ, M.: Multicultural education of children and youth, Diploma Thesis, PdF UMB, Banská Bystrica, 2005

[5] KOVÁČIKOVÁ, D.: On the issues of multicultural education of young generation, Youth and society, 1/2000, pp.16-20

[6] NÁKONEČNÝ, M.: Lexicon of psychology, Praha, 1995

[7] PRŮCHA, J.: Intercultural psychology, $1^{\text {st }}$ edition, Praha, 2004, p. 200, ISBN 80-7178-885-6 